\title{
MANAGEMENT OF ENDOCRINE DISEASE Management of pregnant patients with Cushing's syndrome
}

\author{
M D Bronstein ${ }^{1}$, M C Machado' ${ }^{1}$ and M C B V Fragoso ${ }^{1,2}$ \\ ${ }^{1}$ Neuroendocrine Unit and ${ }^{2}$ Adrenal Unit, Division of Endocrinology and Metabolism, Hospital das Clinicas, \\ University of Sao Paulo Medical School, Avenida Enéas de Carvalho Aguiar, $1558^{0}$ andar Bloco 03, \\ São Paulo, São Paulo 05403-000, Brazil
}

Correspondence should be addressed to $M$ D Bronstein Email mdbronstein@uol.com.br

\begin{abstract}
Progress in the diagnosis and treatment of endocrine diseases has turned pregnancy into a possibility for women with such medical disorders, including Cushing's syndrome (CS). Nevertheless, despite its rarity, pregnancy in patients with CS can be troublesome because of the risk of maternal-fetal complications. Therefore, hypercortisolism, if present, should be surgically or medically controlled in most cases. Moreover, changes in the hypothalamic-pituitary-adrenal axis during normal pregnancy may mislead the diagnosis of CS during this period, because many laboratory assessments suggestive of CS may be present in normal pregnancy, with clinical features mimicking those seen in patients with CS. The aim of the present review is to update the diagnostic approach to this medical condition, mainly for pregnant women without previous diagnosis of CS, and to describe the therapeutic strategies for CS during pregnancy in order to minimize complications for both mother and fetus.
\end{abstract}

\section{Introduction}

Progress in the diagnosis and treatment of endocrine diseases has led to an increase in ovulation rates and has consequently turned pregnancy into a possibility for women with such medical disorders. These achievements include patients with Cushing's syndrome (CS), a condition in which high serum cortisol and androgen levels usually impair the gonadotropic axis. Nevertheless, pregnancy in a setting of hypercortisolism brings risks for both the mother and the fetus, and it is therefore a concern for endocrinologists, gynecologists, and pediatricians. The present review intends: i) to describe the changes in the hypothalamic-pituitary-adrenal (HPA) axis during normal pregnancy, which may mislead the diagnosis of CS during normal pregnancy; ii) to update the diagnostic approach to this medical condition, mainly for pregnant women without a previous diagnosis of CS; and iii) to describe the therapeutic strategies for CS during pregnancy in order to minimize complications for both mother and fetus.

Invited Author's profile:

Marcello D Bronstein, MD, PhD, is Professor of Endocrinology at the University of São Paulo Medical School and Chief of the Neuroendocrine Unit, Division of Endocrinology and Metabolism, Department of Internal Medicine at the Hospital das Clínicas at the same institution. From 2011 to 2012, he was president of the International Pituitary Society. He has published extensively in various international peer-reviewed journals and has written 20 textbook chapters. His main fields of interest and research are the diagnosis and treatment of pituitary tumors and pituitary tumorigenesis.

(C) 2015 European Society of Endocrinology Printed in Great Britain
Published by Bioscientifica Ltd. 


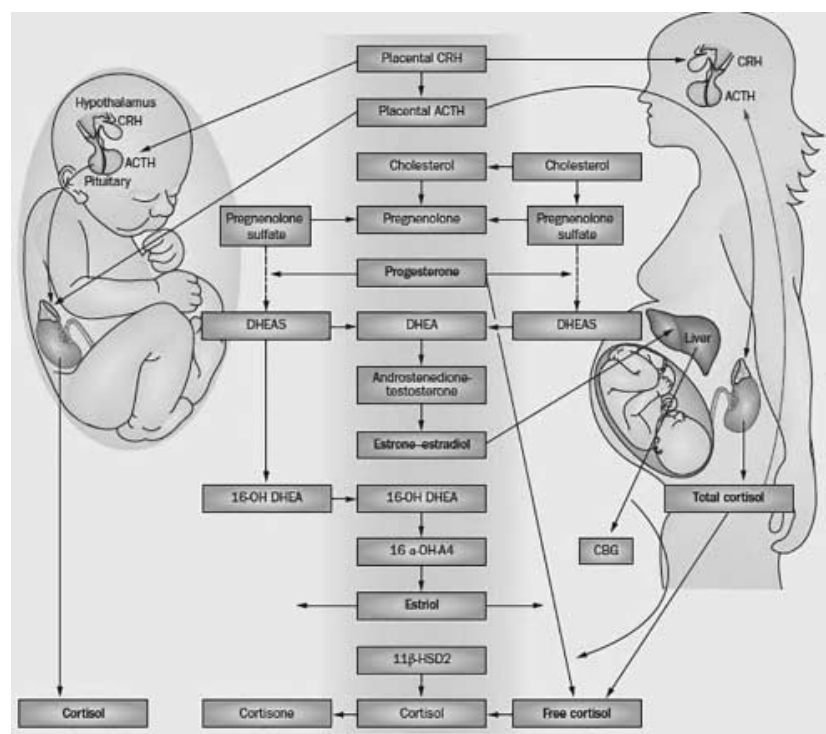

\section{Figure 1}

Hypothalamic-pituitary-adrenal axis during normal pregnancy. The production of cortisol linked to corticosteroid-binding globulin is increased, as is the free fraction. The concentration of ACTH is high, and the adrenal cortex is responsible for stimulus. $16 \alpha$-OH-4A, $16 \alpha$-hydroxyandrostenedione; $\mathrm{CRH}$, corticotropin-releasing hormone. Reproduced with permission from Bronstein MD, Paraiba DB \& Jallad RS. Management of pituitary tumors in pregnancy. Nature Reviews. Endocrinology 20117 301-310. (C) Macmillan Publishers limited.

\section{HPA axis of binary complex maternal-fetus}

The physiological activation of the HPA axis during pregnancy has been proposed to act as a biological clock that times labor and delivery (Fig. 1).

The corticotropin-releasing hormone $(\mathrm{CRH})$, one the most important modulators of the HPA, is not only produced in the hypothalamus but has also been detected in theca and in stromal cells as well as in cells of the ovarian corpora lutea (1). In addition, the epithelial cells of the endometrium encompass $\mathrm{CRH}$ and have been shown to have specific CRH receptors $(2,3)$. This peptide has effects on the maturation of the fetal adrenal, on fetal-placental unit circulation, and also on paracrine effects on the placenta. Its molecular structure is identical to the hypothalamic form (4).

During pregnancy, CRH and adrenocorticotropin (ACTH) plasma levels increase exponentially in the first trimester of gestation as a result of $\mathrm{CRH}$ and ACTH placenta production (Fig. 2). Nevertheless, the HPA axis is protected by a physiological concurrent increase in CRH-binding protein (5). The physiological increase in
CRH/ACTH during pregnancy causes a slight elevation of cortisol levels (serum, salivary, and urinary). Nonetheless, the cortisol secretion maintains a pulsatile and circadian rhythm even during the third trimester when cortisol attains maximal levels (6).

Another aspect to be considered concerns the increase in corticosteroid-binding globulin (CBG) production secondary to high levels of estradiol during pregnancy. The increase in CBG reaches its highest levels at the end of pregnancy and leads to a serum cortisol overestimation by commercial assays that generally measure total serum cortisol levels, which mainly represent the bound fraction with CBG (7). Nevertheless, serum-free cortisol levels also rise around 1.6-fold by the 11th week of pregnancy because of the pregnancy-induced HPA activation (6). Consequently, urinary free cortisol increases up to threefold the normal range (8). Interestingly, the placenta expresses 11- $\beta$ hydroxysteroid dehydrogenase 2 , which

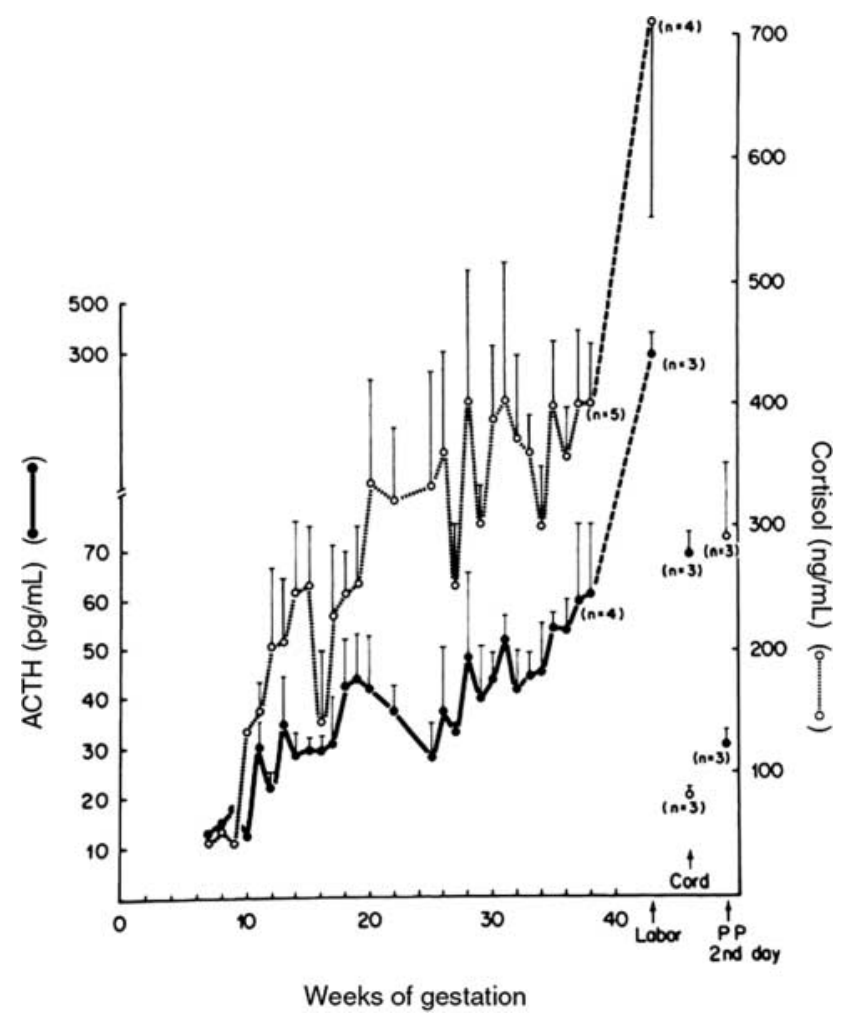

Figure 2

Serial increases in serum cortisol (B) and ACTH (C) during pregnancy in normal controls. Reproduced with permission from Carr BP, Parker CR Jr, Madden JD, MacDonald PC \& Porter JC. Maternal plasma adrenocorticotropin and cortisol relationships throughout human pregnacy. American Journal of Obstetrics and Gynecology 1981139 416-422. (C) Mosby Inc. 
converts cortisol to cortisone and therefore protects the fetus from the high maternal cortisol levels (9). As a consequence of the HPA changes, the stimulation test with exogenous $\mathrm{CRH}$ during pregnancy fails to increase ACTH and cortisol, which recover in few weeks after delivery (10). However, higher doses of CRH can produce an increase in ACTH and cortisol starting during the third trimester (11). Moreover, the suppression of cortisol after a dexamethasone suppression test is attenuated as compared to non-pregnant state (9).

Because of ACTH-induced cell proliferation during pregnancy, maternal adrenal glands gradually become hypertrophic. The circulating fetal CRH is almost exclusively of placental origin, and ACTH can be detected in fetal plasma at 12 weeks gestation (10). The CRH-binding protein is elevated during the first two trimesters of pregnancy, but it decreases considerably in the final trimester, and bioavailable plasmatic $\mathrm{CRH}$ is consequently elevated. The increase in CRH plays a role in the labor process and in fetal lung maturation (12). Fetal adrenals are very large compared to the adult adrenal glands, and the major steroid they produce is DHEAS, in contrast to the preponderance of cortisol detected in the fetal circulation, which appears to come from the maternal source (13). In addition, the fetal adrenal converts placental progesterone into cortisol. Another origin of cortisol is the amniotic fluid, where cortisone is converted into cortisol by choriodecidua.

Around the 4th day postpartum, maternal plasma CRH, ACTH, and cortisol gradually decline to basal levels. The adrenal glands are slightly suppressed, similarly to those in the early stages after successful operation in patients with Cushing's disease (CD), and they normalize at 12 weeks (13). This transient period of CRH suppression might be related to the mood disorders and autoimmune diseases that are frequently observed in postpartum women.

\section{Pregnancy with CS}

Pregnancy is considered a transient physiologic state of 'hypercortisolism'; however, it lacks specific clinical manifestations of CS. Despite its higher prevalence in women of reproductive age, pregnancy with CS is extremely rare because infertility is associated with hypogonadotrophic hypogonadism secondary to cortisol and androgens excess (14).

There is a significant difference between the frequency of etiologies of CS in pregnant and in non-pregnant women. During pregnancy, the incidence of adrenal disorders (particularly adenomas) and CD is 60 and 33\% respectively, in contrast to non-pregnant patients, where the incidence is $15 \%$ for adrenal adenoma and $70 \%$ for CD (1). This preponderance is probably related to the exclusive cortisol production from adrenal adenomas as compared to $\mathrm{CD}$, which exhibits a mixed secretion of cortisol and androgens (15). Lindsay et al. (1), upon reviewing 136 pregnancies in 122 women with CS, described the following etiologies: CD $(n=40)$; adrenal adenoma $(n=56)$; adrenal carcinoma $(n=12)$; ectopic ACTH secretion (EAS) $(n=4)$; Carney's complex $(n=1)$; and ACTH-independent hyperplasia $(n=4)$, possibly resulting from aberrant receptor stimulation.

\section{Diagnosis}

The diagnosis of CS during pregnancy is often a challenge, because we need to cope with three situations: i) patients who become pregnant with previously diagnosed CS (the most straightforward scenario); ii) patients who develop CS during pregnancy; and iii) women who exhibit clinical features of CS, such as striae, hypertension, and diabetes, which are prevalent in normal pregnancy. Concerning clinical differential diagnosis, features such as muscular weakness, larger purple striae (mainly in regions outside of the abdomen) (Fig. 3), and osteoporosis are clues that point to CS instead of normal pregnancy. Hirsutism, resulting from hyperandrogenism, is not a common sign of CS associated with pregnancy, because most cases are pure benign adrenal adenomas that usually feature isolated cortisol secretion (16). Nevertheless, differential diagnosis on a clinical basis is often misleading and therefore needs the additional support of laboratory and imaging procedures.

Hormonal diagnosis of CS during pregnancy may also be a challenge, because high serum and urinary cortisol levels and abnormal cortisol dexamethasone suppression tests occur frequently in normal pregnancies $(4,17)$. Thus, high urinary free cortisol, particularly if it is less than three times the upper lim it normal range, usually cannot differentiate normal pregnancy from CS, especially during the second and third trimesters. The absence of circadian rhythm is probably the best test, seeing as the circadian rhythm is preserved during normal pregnancy, and this points to salivary cortisol as one of the best tools for detection. Nevertheless, to date, threshold values for the diagnosis of CS during pregnancy are not well validated.

Once the diagnosis of CS is confirmed or highly suspected, we must proceed to discover its etiology. Although adrenal adenomas account for $60 \%$ of cases of Cushing's pregnancy, the expected ACTH suppression of this condition, albeit confirmatory, is often not observed, 


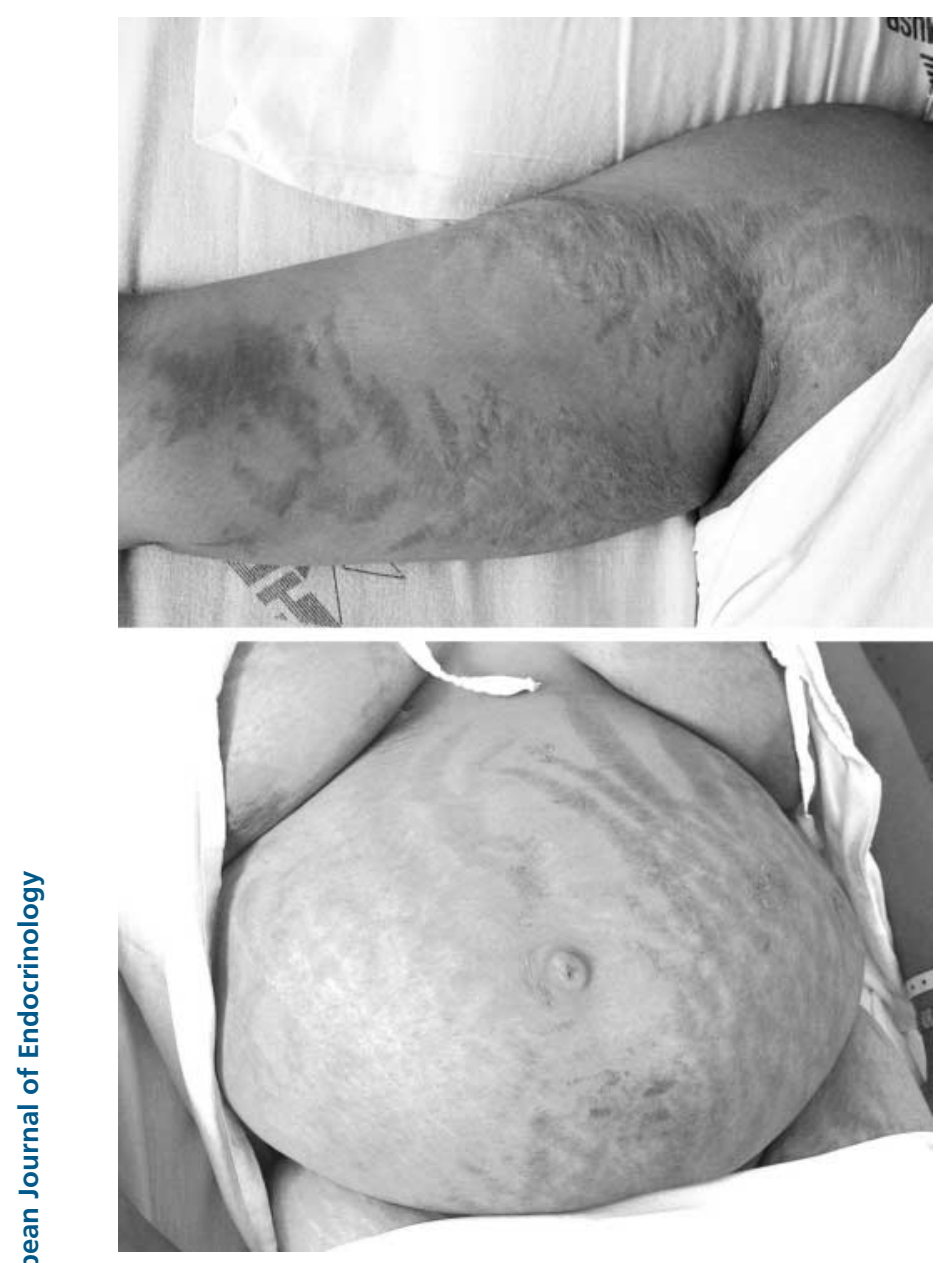

Figure 3

Non-pregnant woman with Cushing's disease exhibiting large striae in the abdomen and arm (HC/FMUSP).

probably because pituitary ACTH can be stimulated by placental CRH or by placental ACTH itself $(17,18)$. Patients with CD diagnosed during pregnancy present ACTH levels in the upper half of the normal range or even higher (17).

A high-dose dexamethasone suppression test could be a clue for differential diagnosis, because, if the results are positive, an adrenal tumor would be unlikely. Nevertheless, a lack of suppression does not rule out ACTH-dependent Cushing's because of the elevated levels of bound cortisol (18).

A distinctive feature of adrenal CS caused by aberrant luteinizing hormone (LH) receptor is the disappearance of hypercortisolism after delivery in conjunction with the cessation of human chorionic gonadotrophin placental production. Of course, this feature is not a diagnostic aid during pregnancy (19) (Fig. 4).

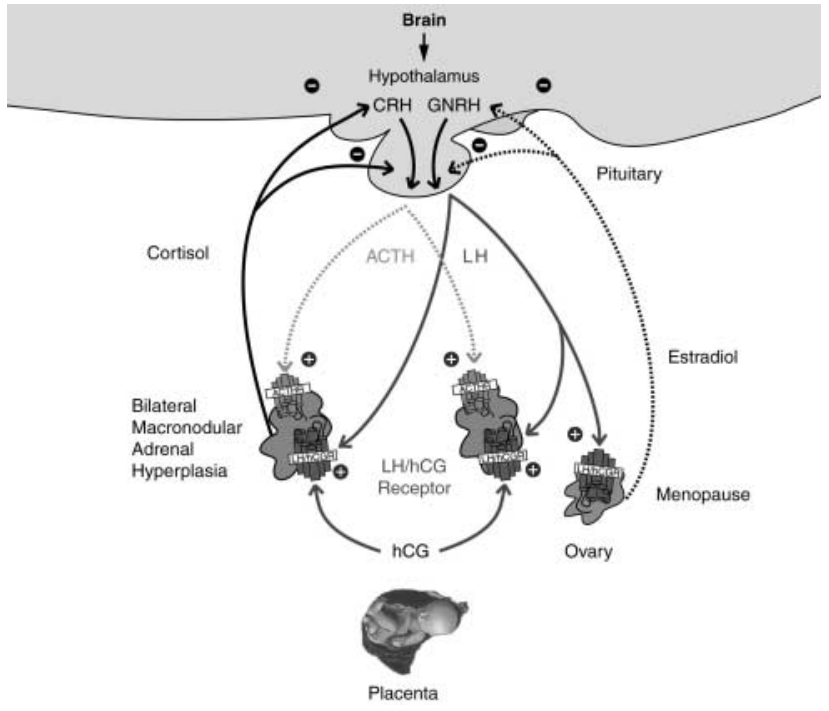

\section{Figure 4}

Illustration of aberrant receptor expression (LH/hCGR) in adrenal cortex causing bilateral macronodular adrenal hyperplasia in a patient with Cushing's syndrome developed during pregnancy. Reproduced with permission from Lacroix A, Ndiaye N, Tremblay J \& Hamet P. Ectopic and abnormal hormone receptors in adrenal Cushing's syndrome. Endocrine Reviews 200122 75-110. (C) The Endocrine Society. 
Table 1 Reports of medications used to treat patients with Cushing's syndrome during pregnancy.

\begin{tabular}{l}
\hline Medication \\
\hline Metyrapone $(17,26,27,30,33,34)$ \\
Ketoconazole $(17,30,31)$ \\
Cyproheptadine (17) \\
Aminoglutethimide (17) \\
Mitotane (17) \\
Cabergoline (31, 32)
\end{tabular}

\begin{tabular}{c}
$\mathbf{n}=\mathbf{2 6}$ \\
\hline 16 \\
4 \\
3 \\
1 \\
1 \\
1 \\
\hline
\end{tabular}

$\begin{array}{r}\hline \% \\ \hline 61 \\ 15 \\ 11 \\ 4 \\ 4 \\ 4 \\ \hline\end{array}$

\begin{tabular}{c} 
Dose $(\mathrm{g} /$ day $)$ \\
\hline $0.5-3.0$ \\
$0.6-1.0$ \\
2.5 \\
\end{tabular}

Comments
Systemic hypertension and preeclampsia risk
Teratogenicity (only in animal studies)
Lack of efficacy
Fetal masculinization
Teratogenic

$n$, number of patients; \%, percentage of total of patients treated.

\section{Treatment of pregnancies with CS}

Approximately 150 cases of pregnancy and endogenous CS have been reported in the literature. Of those, treatment was performed in a subset of patients, but many cases, especially when discovered late in pregnancy, were managed conservatively by just trying to control comorbidities, such as hypertension and diabetes mellitus.

Nonetheless, uncontrolled CS during pregnancy is associated with a high rate of maternal complications (17). Even in treated cases, some patients develop complications, such as preeclampsia and premature delivery.

The most commonly described maternal morbidities include: hypertension (68\%), diabetes or glucose intolerance (25\%), preeclampsia (14\%), osteoporosis and fractures $(5 \%)$, cardiac failure (3\%), psychiatric disorders $(4 \%)$, wound infections (2\%), and maternal death (2\%) (17).

Concerning newborns, a tendency for a higher live birth rate was observed in women who were treated during pregnancy. The more frequent fetal morbidity is prematurity, which occurs in about $43 \%$ of pregnancies. Other described complications include: intrauterine growth retardation $(21 \%)$, stillbirths $(6 \%)$, spontaneous abortion or intrauterine death (5\%), and hypoadrenalism (2\%) (17).

Similarly to non-pregnant women, surgery is usually the first treatment option in pregnant CS patients $(1,17,23,24)$. On the other hand, further options to treat hypercortisolism, such as radiotherapy and mitotane, are contraindicated in this period because of their potential harmful or teratogenic effects and their delayed outcomes (25).

In patients with $\mathrm{CD}$ during pregnancy, $42.5 \%$ were not submitted to specific treatment of hypercortisolism (17). The treated patients were submitted equally to transsphenoidal surgery, medical treatment, or bilateral adrenalectomy. Surgical treatment was performed on ACTH-secreting pituitary adenomas between the end of the first trimester and the early second trimester (12-29 weeks gestation), a period associated with a lower rate of maternal and fetal complications. Several factors can influence the decision to perform surgery, including the etiology, severity, stage of gestation, and therapeutic riskbenefit for the maternal-fetal outcomes (24).

Adrenalectomy for adrenal etiologies of CS, such as adrenal adenomas and carcinomas, was performed with positive results both for hypercortisolism resolution and birth rate (87\%) (23). Additionally, bilateral adrenalectomy can be performed in other situations, especially in non-controlled CD or severe EAS.

Medical therapy, which was generally initiated during the second or third trimesters, is a second treatment option. Of these, treatment with steroidogenesis inhibitors, particularly with metyrapone, was the option used most often (26) (Table 1). This drug was used in $69 \%$ of cases and showed good control of hypercortisolism in most of them, with one report of adrenal insufficiency $(17,27)$. The most worrisome side effects of metyrapone are an increase in precursors such as 11-deoxycorticosterone, worsened hypertension, and an increase in preeclampsia frequency. Although it crosses the placental membrane in animal studies, no neonatal abnormalities have been reported in human patients $(28,29)$. Ketoconazole, the steroidogenesis inhibitor used most often in non-pregnant CS patients, has been utilized less during pregnancy because of its potential side effects, which include an anti-androgenic effect and teratogenicity (only shown in animal studies) $(17,30,31)$. Other adrenal steroidogenesis blockers, such as aminoglutethimide and mitotane, were rarely used, because they were contraindicated as a result of fetal masculinization and teratogenicity respectively (16). Concerning pituitary tumor-directed drugs, in spite of the increasing use of cabergoline for $\mathrm{CD}$, only one patient has reportedly been treated with this dopamine agonist during pregnancy to date (32).

In conclusion, despite its rarity, pregnancy in patients with CS can be troublesome because of maternal-fetal complications. Achievements in the physiology of the corticotrophic axis during pregnancy applied to 
laboratorial assays, improvements in imaging methods, and advancements in pituitary and adrenal surgical approaches have all favorably contributed to the differential diagnosis with normal pregnancy as well as to the reduction of maternal and fetal morbidity and mortality.

\section{Declaration of interest}

The authors declare that there is no conflict of interest that could be perceived as prejudicing the impartiality of the review reported.

\section{Funding}

This research did not receive any specific grant from any funding agency in the public, commercial or not-for-profit sector.

\section{References}

1 Lindsay JR \& Nieman LK. The hypothalamic-pituitary-adrenal axis in pregnancy: challenges in disease detection and treatment. Endocrine Reviews 200526 775-799. (doi:10.1210/er.2004-0025)

2 Sehringer B, Zahradnik HP, Simon M, Ziegler R, Noethling C \& Schaefer WR. mRNA expression profiles for corticotrophin-releasing hormone, urocortin, CRH-binding protein and CRH receptors in human term gestational tissues determined by real-time quantitative RT-PCR. Journal of Molecular Endocrinology 200432 339-348. (doi:10.1677/jme.0.0320339)

3 Wetzka B, Sehringer B, Schafer WR, Biller S, Hör C, Benedek E, Deppert WR \& Zahradnik HP. Expression patterns of CRH, CRH receptors, and $\mathrm{CRH}$ binding protein in human gestational tissue at term. Experimental and Clinical Endocrinology \& Diabetes 2003111 154-161. (doi:10.1055/s-2003-39778)

4 Carr BP, Parker CR Jr, Madden JD, MacDonald PC \& Porter JC. Maternal plasma adrenocorticotropin and cortisol relationships throughout human pregnacy. American Journal of Obstetrics and Gynecology 1981139 416-422.

5 Behan DP, Linton EA \& Lowry PJ. Isolation of the human plasma corticotrophin-releasing factor-binding protein. Journal of Endocrinology 1989122 23-31. (doi:10.1677/joe.0.1220023)

6 Demey-Ponsart E, Foidart JM, Sulon J \& Sodoyez JC. Serum CBG, free and total cortisol and circadian patterns of adrenal function in normal pregnancy. Journal of Steroid Biochemistry 198216 165-169. (doi:10.1016/0022-4731(82)90163-7)

7 Nolten WE, Lindheimer MD, Rueckert PA, Oparil S \& Ehrlich EN. Diurnal patterns and regulation of cortisol secretion in pregnancy. Journal of Clinical Endocrinology and Metabolism 198051 466-472. (doi:10.1210/jcem-51-3-466)

8 Jung C, Ho JT, Torpy DJ, Rogers A, Doogue M, Lewis JG, Czajko RJ \& Inder WJ. A longitudinal study of plasma and urinary cortisol in pregnancy and postpartum. Journal of Clinical Endocrinology and Metabolism 201196 1533-1540. (doi:10.1210/jc.2010-2395)

9 Odagiri E, Ishiwatari N, Abe Y, Jibiki K, Adachi T, Demura R, Demura H \& Shizume K. Hypercortisolism and the resistance to dexamethasone suppression during gestation. Endocrinologia Japonica 198835 685-690. (doi:10.1507/endocrj1954.35.685)

10 Schulte HM, Weisner D \& Allolio B. The corticotrophin releasing hormone test in late pregnancy: lack of adrenocorticotrophin and cortisol response. Clinical Endocrinology 1990 33 99-106. (doi:10.1111/j. 1365-2265.1990.tb00470.x)
11 Suda T, Iwashita M, Ushiyama T, Tozawa F, Sumitomo T, Nakagami Y, Demura H \& Shizume K. Responses to corticotropin-releasing hormone and its bound and free forms in pregnant and nonpregnant women. Journal of Clinical Endocrinology and Metabolism 198969 38-42. (doi:10.1210/jcem-69-1-38)

12 Linton EA, Perkins AV, Woods RJ, Eben F, Wolfe CD, Behan DP, Potter E, Vale WW \& Lowry PJ. Corticotropin releasing hormonebinding protein (CRH-BP): plasma levels decrease during the third trimester of normal human pregnancy. Journal of Clinical Endocrinology and Metabolism 199376 260-262.

13 Pivonello R, De Martino MC, Auriemma RS, Alviggi C, Grasso LF, Cozzolino A, De Leo M, De Placido G, Colao A \& Lombardi G. Pituitary tumors and pregnancy: the interplay between a pathologic condition and a physiologic status. Journal of Endocrinological Investigation 201437 99-112. (doi:10.1007/s40618-013-0019-8)

14 Prebtani AP, Donat D \& Ezzat S. Worrisome striae in pregnancy. Lancet 2000355 1692. (doi:10.1016/S0140-6736(00)02242-X)

15 Abdelmannan D \& Aron DC. Adrenal disorders in pregnancy. Endocrinology and Metabolism Clinics of North America 201140 779-794. (doi:10.1016/j.ecl.2011.09.001)

16 McClamrock HD \& Adashi EY. Gestational hyperandrogenism. Fertility and Sterility $1992 \mathbf{5 7} 257-274$.

17 Lindsay JR, Jonklaas J, Oldfield EH \& Nieman LK. Cushing's syndrome during pregnancy: personal experience and review of the literature. Journal of Clinical Endocrinology and Metabolism 200590 3077-3083. (doi:10.1210/jc.2004-2361)

18 Arnaldi G, Angeli A, Atkinson AB, Bertagna X, Cavagnini F, Chrousos GP, Fava GA, Findling JW, Gaillard RC, Grossman AB et al. Diagnosis and complications of Cushing's syndrome: a consensus statement. Journal of Clinical Endocrinology and Metabolism $2003 \mathbf{8 8}$ 5593-5602. (doi:10.1210/jc.2003-030871)

19 Lacroix A, Ndiaye N, Tremblay J \& Hamet P. Ectopic and abnormal hormone receptors in adrenal Cushing's syndrome. Endocrine Reviews 200122 75-110.

20 Nieman LK, Biller BM, Findling JW, Newell-Price J, Savage MO, Stewart PM \& Montori VM. The diagnosis of Cushing's syndrome: an Endocrine Society Clinical Practice Guideline. Journal of Clinical Endocrinology and Metabolism 200893 1526-1540. (doi:10.1210/jc.2008-0125)

21 Pinette MG, Pan YQ, Oppenheim D, Pinette SG \& Blackstone J. Bilateral inferior petrosal sinus corticotropin sampling with corticotropinreleasing hormone stimulation in a pregnant patient with Cushing's syndrome. American Journal of Obstetrics and Gynecology 1994171 563-564. (doi:10.1016/0002-9378(94)90303-4)

22 Cabezon C, Bruno OD, Cohen M, Garcia S \& Gutman RA. Twin pregnancy in a patient with Cushing's disease. Fertility and Sterility 1999 72 371-372. (doi:10.1016/S0015-0282(99)00261-7)

23 Vilar L, Freitas Mda C, Lima LH, Lyra R \& Kater CE. Cushing's syndrome in pregnancy: an overview. Arquivos Brasileiros de Endocrinologia e Metabologia 200751 1293-1302.

24 Bronstein MD, Paraiba DB \& Jallad RS. Management of pituitary tumors in pregnancy. Nature Reviews. Endocrinology 20117 301-310. (doi:10.1038/nrendo.2011.38)

25 Leiba S, Weinstein R, Shindel B, Lapidot M, Stern E, Levavi H, Rusecki Y $\&$ Abramovici A. The protracted effect of o, $\mathrm{p}^{\prime}$-DDD in Cushing's disease and its impact on adrenal morphogenesis of young human embryo. Annales d'Endocrinologie 198950 49-53.

26 Lim WH, Torpy DJ \& Jeffries WS. The medical management of Cushing's syndrome during pregnancy. European Journal of Obstetrics, Gynecology, and Reproductive Biology 2013168 1-6. (doi:10.1016/ j.ejogrb.2012.12.015)

27 Blanco C, Maqueda E, Rubio JA \& Rodriguez A. Cushing's syndrome during pregnancy secondary to adrenal adenoma: metyrapone treatment and laparoscopic adrenalectomy. Journal of Endocrinological Investigation 200629 164-167. (doi:10.1007/BF03344091)

28 Hana V, Dokoupilova M, Marek J \& Plavka R. Recurrent ACTHindependent Cushing's syndrome in multiple pregnancies and its 
treatment with metyrapone. Clinical Endocrinology 200154 277-281. (doi:10.1046/j.1365-2265.2001.01055.x)

29 Connell JM, Cordiner J, Davies DL, Fraser R, Frier BM \& McPherson SG. Pregnancy complicated by Cushing's syndrome: potential hazard of metyrapone therapy. Case report. British Journal of Obstetrics and Gynaecology 198592 1192-1195. (doi:10.1111/j.1471-0528.1985.tb03037.x)

30 Boronat M, Marrero D, Lopez-Plasencia Y, Barber M, Schamann Y \& Novoa FJ. Successful outcome of pregnancy in a patient with Cushing's disease under treatment with ketoconazole during the first trimester of gestation. Gynecological Endocrinology 201127 675-677. (doi:10.3109/ 09513590.2010.521268)

31 Berwaerts J, Verhelst J, Mahler C \& Abs R. Cushing's syndrome in pregnancy treated by ketoconazole: case report and review of the literature. Gynecological Endocrinology 199913 175-182. (doi:10.3109/ 09513599909167552)

32 Woo I \& Ehsanipoor RM. Cabergoline therapy for Cushing disease throughout pregnancy. Obstetrics and Gynecology 2013122 485-487. (doi:10.1097/AOG.0b013e31829e398a)

33 Achong N, D'Emden M, Fagermo N \& Mortimer R. Pregnancyinduced Cushing's syndrome in recurrent pregnancies: case report and literature review. Australian \& New Zealand Journal of Obstetrics \& Gynaecology 201252 96-100. (doi:10.1111/j.1479-828X.2011. 01388.x)

34 Mundra V, Solorzano C \& DeSantis P. Cushing syndrome: a rare ocurrence in pregnancy. Endocrinologist 201020 165-167. (doi:10.1097/TEN.0b013e3181ecb06a)

Received 19 December 2014

Revised version received 24 February 2015

Accepted 14 April 2015 